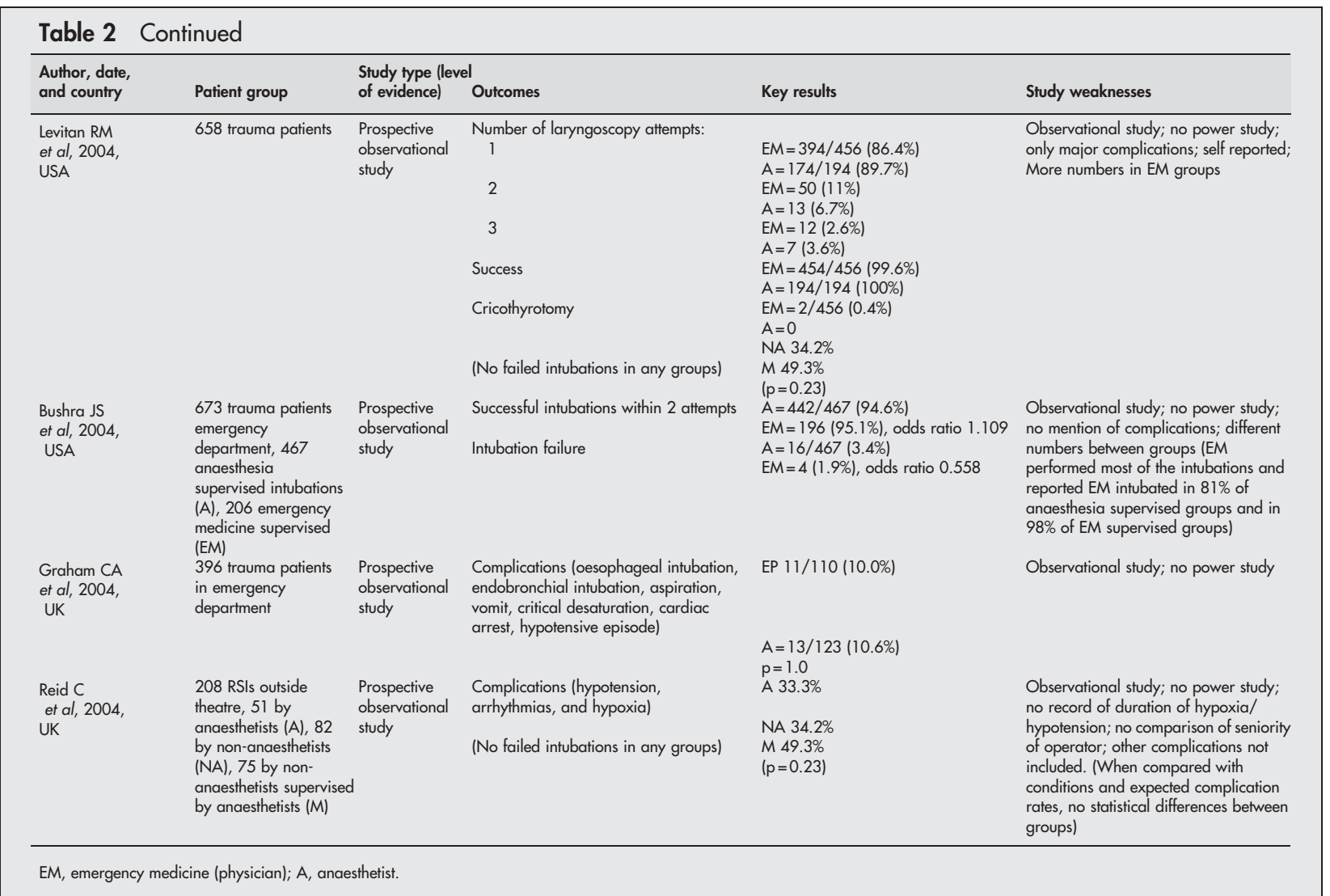

Taryle DA, Chandler JE, Good JT Jr, et al. Room intubations-complications and survival. Chest 1979;75:541-3.

Dufour DG, Larose DL, Clement SC. Rapid sequence intubation in the emergency department. J Emerg Med 1995;13:705-10.

Sakles JC, Laurin EG, Rantapaa AA, et al. Management in the emergency department: a one-year study of 610 tracheal intubations. Ann Emerg Med 1998;31:325-32.

Omert L, Yeaney W, Mizikowski S, et al. Role of emergency medicine physician in airway management of the trauma patient. J Trauma 2001;51:1065-8.

Butler JM, Clancy M, Robinson N, et al. An observational survey of emergency department rapid sequence intubation. Emerg Med J 2001;18:343-8.

Tam AY, Lau FL. A prospective study of tracheal intubation in an emergency department in Hong Kong. Eur J Emerg Med 2001;8:305-10.

Wong E, Fong YT. Trauma airway experience by emergency physicians. Eur J Emerg Med 2003;10:209-12.

Wong E, Fong YT, Ho KK. Emergency airway management-experience of a tertiary hospital in South-East Asia. Resuscitation 2004;61:349-55.

Levitan RM, Rosenblatt B, Meiner EM, et al. Alternating day emergency medicine and anesthesia resident responsibility for management of the trauma airway: a study of laryngoscopy performance and intubation success. Ann Emerg Med 2004;43:48-53.

Bushra JS, McNeil B, Wald DA, et al. A comparison of trauma intubations managed by anesthesiologists and emergency physicians. Acad Emerg Med 2004;11:66-70.

Graham CA, Beard D, Henry JM, et al. Rapid sequence intubation of trauma patients in Scotland. J Trauma 2004;56:1123-6.

Reid C, Chan L, Tweeddale M. The who, where, and what of rapid sequence intubation: prospective observational study of emergency RSI outside the operating theatre. Emerg Med J 2004;21:296-301.

\section{Absorbable sutures in paediatric lacerations}

\section{Report by Robert Evans, Resident Physician Checked by Jeff Jones, Research Director Grand Rapids MERC/MSU, USA doi: $10.1136 /$ emj.2005.032615}

\section{Abstract}

A short cut review was carried out to establish whether absorbable sutures offered any benefits over non-absorbable sutures in the treatment of childhood facial lacerations. A total of 31 papers were found, of which one presented the best evidence to answer the clinical question. The author, date and country of publication, patient group studied, study type, relevant outcomes, results, and study weaknesses of this best paper are tabulated. We conclude that absorbable sutures appear to be as good as and show a trend towards benefit in the treatment of paediatric lacerations.

\section{Three part question}

In [paediatric patients with traumatic lacerations], does [the use of absorbable sutures compared with non-absorbable sutures] [increase the rates of complications and long term cosmesis]?

\section{Clinical scenario}

A 10 year old boy presents after a suffering a laceration on his lower leg from a snow skiing accident. It cannot be closed using glue. You would like to save the child the pain and discomfort of suture removal. You wonder if absorbable sutures would increase the rate of complications or scarring.

\section{Search strategy}

Medline 1966-November 2005 using the OVID interface; Cochrane Library, 2005: [(exp lacerations or laceration.mp) AND (exp sutures/or suture.mp) AND (exp treatment outcome/ OR exp cosmetic techniques/ OR exp wound infection/ )]. LIMIT to human AND English AND "all child (0 to 18 years)". Cochrane Database of Systematic Reviews: [Suture and absorbable]

\section{Search outcome}

Medline: 31 papers found of which 30 were irrelevant or of insufficient quality (see table 3 for the single best paper). Cochrane: 23 papers found, no new additional references found. 


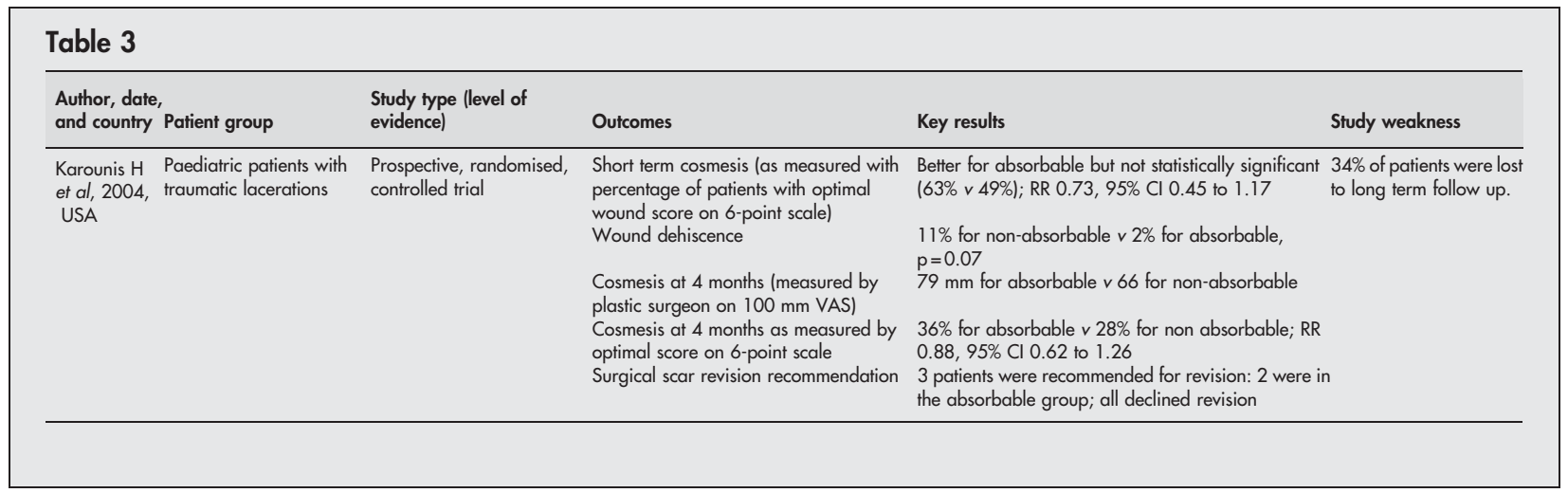

\section{Comment(s)}

The use of absorbable sutures in children has the benefit of avoiding the emotional and physical trauma and cost of suture removal. The only prospective randomised controlled trial showed no difference between absorbable sutures and non-absorbable sutures in the rate of complications as well as cosmesis. However, too many patients were lost to long term follow up.

\section{- CLINICAL BOTTOM LINE}

Absorbable sutures appear to be as good as, and show a trend towards benefit, in paediatric laceration.

Karounis $\mathrm{H}$, Gouin $\mathrm{S}$, Eisman $\mathrm{H}$, et al. A randomized, controlled trial comparing long-term cosmetic outcomes of traumatic pediatric lacerations repaired with absorbable plain gut versus nonabsorbable nylon sutures Acad Emerg Med 2004;11:730-5.

\section{Smectite for acute diarrhoea in children}

\section{Report by Zui-Shen Yen, Emergency Physician Checked by Mei-Shu Lai, Emergency Physician National Taiwan University Hospital, Taiwan doi: $10.1136 / \mathrm{emj} .2005 .032623$}

Abstract

A short cut review was carried out to establish whether smectite was a useful therapy in acute diarrhoea. A total of 21 papers were found of which five presented the best evidence to answer the clinical question. The author, date and country of publication, patient group studied, study type, relevant outcomes, results, and study weaknesses of these best papers are tabulated. The clinical bottom line is that oral smectite appears to be effective at shortening the duration of the diarrhoea in children with acute diarrhoea rehydrated with oral rehydration solution.

\section{Three part question}

In [children with acute diarrhoea] is [the use of smectite with oral rehydration solution better than oral rehydration solution alone] at [shortening the duration of diarrhoea]?

\section{Clinical scenario}

A 12 month old boy with acute diarrhoea is brought to the emergency department by his parents. He tolerates oral rehydration solution well but his parents still worry very much about his frequent loose stools. You wonder if the use of smectite would provide any additional benefit.

\section{Search strategy}

Medline 1966-August 2005, Embase 1966-August 2005: $\{$ (dioctahedral\$.mp OR smect\$.mp) AND (exp diarrhea OR exp gastroenteritis OR diarrh\$.mp)\} LIMIT to human AND English. Embase: $\left\{\right.$ (diactahedral* ${ }^{*}$ OR smect $\left.^{*}\right)$ AND ('diarrhea'/exp OR 'gastroenteritis'/exp OR diarrh*)\} LIMIT to human AND English; Cochrane Library: [smectite]

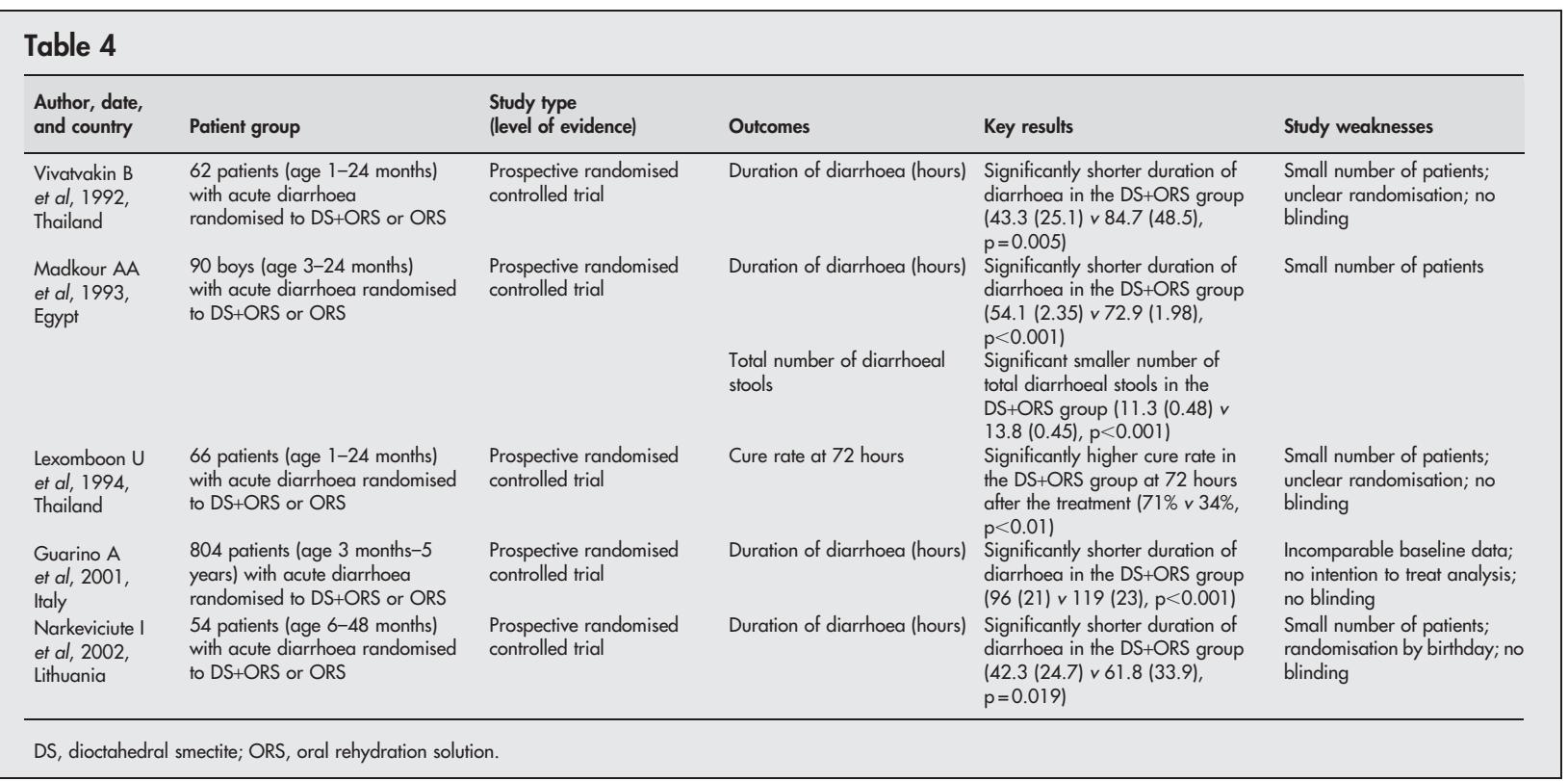

